\title{
Construindo cenários de mobilidade acadêmica: o processo de internacionalização em uma universidade comunitária
}

\author{
Building academic mobility scenarios: the \\ internationalization process at a community \\ university
}

Construyendo escenarios de movilidad académica: el proceso de internacionalización en una universidad comunitaria

Silvia Regina Canan ${ }^{1}$

Edite Maria Sudbrack ${ }^{1}$

Thais Campos da Silva ${ }^{1}$

DOI: http://dx.doi.org/10.20435/serie-estudos.v0i0.1387

\begin{abstract}
Resumo: $O$ artigo em tela retrata os resultados parciais de uma pesquisa quali/quantitativa sobre o processo de internacionalização no âmbito de uma universidade comunitária do Rio Grande do Sul, RS, situada na região noroeste do estado. O projeto, financiado pela Fapergs, foi desenvolvido no Núcleo de Estudos e Pesquisas em Processos de Educação Superior (NEPPES), o qual integra a Rede GIEPES (Grupo Internacional de Estudos e Pesquisas em Educação Superior), e teve por objetivo: "Investigar como a URI tem construído seu processo de internacionalização, levando em consideração os documentos oficiais da universidade, os Projetos Pedagógicos dos Cursos de Graduação, os Projetos dos Programas Stricto Sensu, tendo em vista que a internacionalização vem sendo considerada, hoje, a quarta missão da universidade". Ao investigar a temática, foi possível concluir que houve um avanço no conceito de internacionalização e uma maior integração por meio de ações e convênios com universidades latino-americanas, contrariando os primeiros indícios de internacionalização que apontavam para um número muito mais expressivo de convênios assinados com universidades europeias; e, por fim, que, mesmo que o número de acadêmicos e professores que vivenciaram processos de mobilidade acadêmica pareça ser baixo em relação a grandes universidades, ele foi muito significativo se considerarmos o locus onde desenvolvemos a pesquisa.
\end{abstract}

Palavras-chave: internacionalização; mobilidade acadêmica; Educação Superior.

${ }^{1}$ Universidade Regional Integrada do Alto Uruguai e das Missões (URI), Itapajé, Rio Grande do Sul, Brasil. 


\begin{abstract}
This article portrays the partial results of a quali/quantitative research about the internationalization process within a community university of Rio Grande do Sul, RS, located in the northwest of the state. The project, funded by Fapergs, was developed at the Center for Studies and Research in Higher Education Processes (NEPPES), which is part of the GIEPES Network (Network of the International Group for Studies and Research in Higher Education). It aimed: "To investigate how URI has built its internationalization process, taking into account the official documents of the university, the Pedagogical Projects of the Undergraduate Courses, the Projects of the Stricto Sensu Programs, seeing that the internationalization has been considered, nowadays, the fourth university mission". By investigating the theme, it was possible to conclude that there was an advance in the concept of internationalization and a greater integration through actions and agreements with Latin American universities, contradicting the first signs of internationalization that pointed to a much more expressive number with signed agreements with European universities; and finally that, even though the numbers of academics and professors who have experienced academic mobility processes appear to be low relative to large universities, it has been very significant if we consider the locus where we develop the research.
\end{abstract}

Keywords: internationalization; academic mobility; Higher Education.

Resumen: Este artículo retrata los resultados parciales de una investigación cualitativa/cuantitativa sobre el proceso de internacionalización dentro de una universidad comunitaria del Rio Grande do Sul, RS, ubicada en el noroeste del estado. El proyecto, financiado por la Fapergs, fue desarrollado en el Centro de Estudios e Investigación en Procesos de Educación Superior (NEPPES), que forma parte de la Red GIEPES (Grupo Internacional de Estudios e Investigación en Educación Superior), y tenía como objetivo: "Investigar cómo URI ha construido su proceso de internacionalización, teniendo en cuenta los documentos oficiales de la universidad, los Proyectos Pedagógicos de los cursos de pregrado, los Proyectos de los programas Stricto Sensu, teniendo en cuenta que se ha considerado la internacionalización, hoy, la cuarta misión de la universidad". Al investigar el tema, fue posible concluir que hubo un avance en el concepto de internacionalización y una mayor integración a través de acciones y acuerdos con universidades latinoamericanas, contradiciendo los primeros signos de internacionalización que apuntaban a un número mucho más significativo de acuerdos firmados con las universidades europeas; y finalmente que, aunque el número de académicos y profesores que han experimentado procesos de movilidad académica parece ser bajo en relación con las grandes universidades, ha sido muy significativo si consideramos el lugar donde desarrollamos la investigación.

Palabra clave: internacionalización; movilidad académica; Educación Superior.

\title{
1 INTRODUÇÃO
}

O presente artigo apresenta os resultados parciais de uma pesquisa realizada em uma universidade comunitária, por meio de um estudo quali/quantitativo, abordando o processo de internacionalização no âmbito da instituição estudada, a qual está situada na região noroeste do estado do Rio Grande do Sul, RS. O projeto teve financiamento da Fapergs e foi desenvolvido no Núcleo de Estudos e Pesquisas em Processos de Educação Superior (NEPPES), o qual integra a Rede GIEPES (Grupo 
Internacional de Estudos e Pesquisas em Educação Superior). A pesquisa teve como objetivo geral: investigar como a Universidade Regional Integrada do Alto Uruguai e das Missões (URI) tem construído seu processo de internacionalização. Parte dos estudos foi desenvolvida por meio de uma pesquisa documental, a partir dos documentos oficiais da universidade, dos Projetos Pedagógicos dos Cursos de Graduação e dos Projetos dos Programas Stricto Sensu. O tema assumiu especial importância, tendo em vista os estudos que vêm sendo desenvolvidos nessa área, que, em alguns casos, apresenta a internacionalização como a quarta missão da universidade. Nessa perspectiva, ao nos aprofundarmos na temática, foi possível concluir que o conceito de internacionalização, na URI, foi sendo modificado ao longo dos anos, tendo avançado de uma ideia de assinatura de convênios com universidades de outros países para um processo de trocas de saberes, pesquisas conjuntas, eventos, entre outros. Além disso, foi possível identificar uma maior integração por meio de ações e convênios com universidades latino-americanas, contrariando os primeiros indícios de internacionalização, que apontavam para um número muito mais expressivo de convênios assinados com universidades europeias. Por fim, em relação a questões que envolvem mobilidade, ainda que o número de acadêmicos e professores que vivenciaram processos de mobilidade acadêmica possa parecer baixo, em relação a universidades maiores e de maior tradição, ele foi muito significativo se considerarmos o locus onde desenvolvemos a pesquisa.

O texto será dividido em três partes: "Internacionalização: conceito ou conceitos?", em que trabalharemos o conceito de internacionalização à luz dos autores que estudam a temática, confrontando-o com os documentos da URI; "Mobilidade acadêmica: ação estratégica para a internacionalização da Educação Superior", parte em que traremos aspectos teóricos sobre a mobilidade acadêmica; e, por fim: “A mobilidade acadêmica na URI: oportunidades?", na qual apresentaremos parte dos dados de uma pesquisa sobre a temática desenvolvida no âmbito da URI, com professores e alunos.

Ainda que o tema nos reporte à Idade Média, no Brasil, como no mundo, ele nunca atingiu patamares tão elevados e nem foi tão discutido quanto é atualmente. As razões para tal debate são muitas, entre elas, podemos apontar a necessidade de inserção das universidades no processo de globalização mundial, a possibilidade de oportunizar experiências de conhecimentos, cultura, trocas de 
vivências, ou ainda para realizar estudos na modalidade stricto sensu, na dupla titulação, na formação sandwich, na formação em cotutela, na formação integral em outro país, nos diplomas conjuntos, entre outros. Seja qual for a razão, tem sido uma das portas para a formação e para estimular novos campos de atuação.

Nesse processo, a mobilidade acadêmica aparece como uma das possibilidades da internacionalização e é a partir dela que vamos refletir. Essa modalidade ganhou notada evidência no Brasil, com a criação do Programa Ciência sem Fronteiras, que representou um marco na abertura de possibilidades, na perspectiva da mobilidade de estudantes de todo o país para os mais diversos países e continentes do mundo.

Nessa perspectiva, os dados da mobilidade estudantil dos anos de 2013 a 2019, que aqui serão apresentados, dão uma ideia de como esse processo se deu na URI, mostrando que, nessa Instituição, embora ainda possamos crescer muito nesse quesito, a mobilidade constitui-se num grande espaço para o desenvolvimento da internacionalização. Para além dos números, traremos uma breve discussão sobre o significado desse processo no âmbito da universidade.

\section{INTERNACIONALIZAÇÃO: CONCEITO OU CONCEITOS?}

Antes de trazermos dados a respeito da internacionalização na URI, entendemos importante a compreensão de conceitos que permitem, posteriormente, entender os processos vividos na instituição. A tentativa de aproximação ao conceito de internacionalização exige a distinção da concepção de transnacionalização. A internalização está mais afeta aos atributos da solidariedade e dos diálogos interculturais, já a transnacionalização pode ser visualizada enquanto processo de mercadorização ou de dominação (AZEVEDO, 2015). Para Morosini (2006), as concepções de internacionalização são variadas e complexas, passando da relação entre universidade e conhecimento às que se apoiam na concepção de globalização, interação ou transnacionalização.

Nesse entendimento, podemos dizer que a concepção de internacionalização, no âmbito da URI, dialoga com o conceito abordado por Knight (1994), de internacionalização como processo, que é definida como sendo um mecanismo de integração da dimensão internacional/intercultural ao ensino, à pesquisa e aos serviços de uma universidade. 
De acordo com Santos Filho (2018, p. 171), considerando os muitos vieses assumidos pela internacionalização, os níveis e as realidades atuais:

En esa definición, la internacionalización tiene como característica un proceso dinámico que va hacia más allá de la simple realización de actividades en el ámbito internacional, considerándose precario el uso de ese criterio como indicador del grado de internacionalización de una institución de educación superior. (SANTOS FILHO, 2018, p. 171).

Nas palavras de Santos Filho (2018), a partir do que defende Knight (1994), o processo de internacionalização é muito dinâmico e vai muito além da realização de atividades de âmbito internacional. O incremento da globalização econômica, política e cultural exerce impactos significativos sobre a internacionalização da educação e provoca o surgimento de movimentos que delineiam um ambiente acadêmico distinto, como o incremento da mobilidade estudantil, o crescimento do ensino a distância, a consolidação da dimensão internacional das atividades de ensino e pesquisa e o surgimento de padrões internacionais de currículos.

No entendimento de Knight e De Wit (2004, p. 11), "a internacionalização acadêmica como processo de uma dimensão internacional, intercultural e/ou global nos objetivos, funções e ofertas de educação pós-secundária, é uma definição amplamente aceita e difundida na comunidade acadêmica".

Sob esse viés, segundo Trevisol e Fávero (2019, p. 5),

A internacionalização da Educação Superior inclui a mobilidade de estudantes e professores, investigação e desenvolvimento de pesquisa com equipes multidisciplinares e compostas por membros de países diferentes, internacionalização de currículos, alinhamento de procedimentos, estruturas e sistemas de avaliação, a certificação e o uso de critérios comuns de qualidade e o recrutamento de estudantes e docentes estrangeiros.

A partir da perspectiva apontada, concordamos com Morosini (2006) de que as características da educação estão intimamente imbricadas com o processo de globalização e com as determinações oriundas de organismos internacionais multilaterais.

[...] é no sistema de ensino superior que se verifica o maior impacto. Isto porque a globalização considera como um dos principais valores o conhecimento e, neste, o advindo de patamares superiores, onde a busca de educação e certificação continuada se faz presente. A universidade adquire um valor 
máximo e a concepção de liberdade acadêmica, símbolo da intocabilidade do ensino superior, passa a sofrer impacto. (MOROSINI, 2006, p. 112).

Esses impactos sobre a Educação Superior, apontados pela autora, implicam na diversidade de possibilidades que vão surgindo, também, no campo da internacionalização, dando-Ihe novos sentidos. Eles perpassam pela ampliação das formas que envolvem além da mobilidade acadêmica, criação de eventos conjuntos, inserção em cursos de graduação e pós-graduação lato e stricto sensu, criação e participação em programas, projetos e grupos de pesquisa, entre outras formas de integração, o que tem sido fundamental para que o conceito e o sentido da internacionalização tomem contornos cada vez mais complexos, fato que tem contribuído também para o entendimento da URI acerca da internacionalização, ampliando sua visão em relação aos primeiros ensaios nesse campo.

Estudo nos documentos da IES demonstra os avanços que as ações pensadas nessa área vêm sofrendo, passando por mudanças que têm um significado importante para a consolidação da internacionalização, fato que denota a importância, também, do avanço conceitual, uma vez que, conforme destaca Santos Filho (2018, p. 172), "La internacionalización es un proceso dinámico, es decir, un esfuerzo continuado de cambio o evolución y no es un conjunto de actividades aisladas".

No caso da universidade em tela, isso tem muito a ver com o avanço que vai dos convênios assinados pelos Reitores que pouco resultaram em ações efetivas entre a universidade e outras instituições, passando pelo conceito que vai sendo incorporado, discutido, pensado, tomando forma e tornando-se mais efetivo e mais próximo das relações institucionais que passam a nascer a partir dos grupos de pesquisa, de atividades de extensão, dos encontros em eventos e viagens de estudo, entre outros, resultando em novas experiências que têm enriquecido a instituição por meio de seus cursos, tanto de graduação quanto de pós-graduação, especialmente o stricto sensu.

Em se tratando de convênios, inicialmente, havia uma aproximação maior com países europeus, já que no momento da consolidação da universidade (a partir da fusão de antigas fundações isoladas), no início dos anos de 1990, os olhares de boa parte das universidades brasileiras estavam voltados para aquele cenário, tendo como referência não somente as universidades que serviram, por séculos, de modelo para o mundo, como também a proximidade da língua que, 
em certa medida, devido às fronteiras da própria URI com países de origem hispânica, permitia melhor comunicação.

Dados coletados no site da Reitoria da URI sobre os convênios internacionais vigentes (até o presente momento) mostram que, agora, há um equilíbrio em número de convênios entre universidades da América Latina e universidades da Europa e dos EUA, entre outras (com uma pequena vantagem dessas últimas). Essa mudança permitiu que o nascedouro de muitos processos de internacionalização se desenvolva, também, no âmbito dos países latino-americanos, como podemos visualizar no gráfico abaixo:

Gráfico 1 - Países conveniados e número de convênios

\section{Países conveniados e número de convênios}

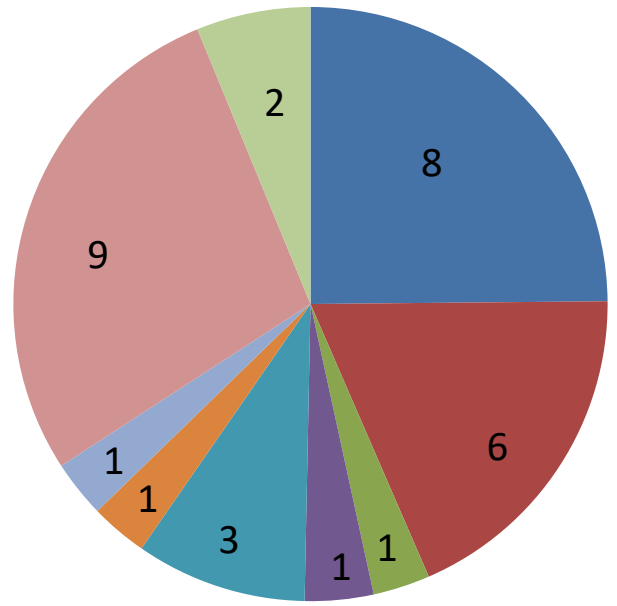

Portugal

- Itália

- Alemanha

- Finândia

- Espanha

Moçambique

EUA

Argentina

Uruguai

Fonte: Construído pelas autoras, a partir de dados da pesquisa.

Sob diferentes prismas, parece haver uma tendência maior de aproximação com os países da Ibero-América, cujos problemas, tensionamentos, conquistas e produções encontram campo fértil para serem estudados e desenvolvidos. Isso tem feito nascer muitos grupos de pesquisas, que vão se constituindo e se construindo, a muitas mãos, entre pares que comungam interesses no campo do ensino, da pesquisa e da extensão. 
Passado pouco mais de um quarto de século da criação da URI (sua Portaria de Reconhecimento data de 19 de maio de 1992), esse cenário assume novas perspectivas e, hoje, a internacionalização é uma realidade que vai se impondo, consolidando-se e trazendo novos desafios e necessidades.

\section{MOBILIDADE ACADÊMICA: AÇÃO ESTRATÉGICA PARA A INTERNACIONALIZAÇÃO DA EDUCAÇÃO SUPERIOR}

A mobilidade acadêmica é hoje uma das principais estratégias de internacionalização, embora não se trate de um fenômeno novo no contexto educacional, pois, segundo Charle e Verger (1996), desde a Idade Média as populações universitárias realizavam mobilidade, não havendo à época fronteiras que se opunham à circulação dos homens, tampouco à validade universal de diplomas conquistados. Castro e Neto (2012), no entanto, lembram que esse processo não englobava da mesma forma todas as universidades, sendo mais restrito às grandes universidades, como as de Paris e Bolonha, pois eram as mais atrativas para os estudantes que vinham de diferentes localidades.

Santos e Almeida Filho (2012) abordam que a movimentação de acadêmicos entre centros de saber pode ser considerada a primeira manifestação de internacionalização universitária. Mesmo não sendo um fenômeno recente, percebemos que, no decorrer da história, a mobilidade vai se reestruturando em virtude do processo de globalização e das atuais estratégias de internacionalização da Educação Superior. A Declaração Mundial de Educação Superior, aprovada no transcurso da conferência da UNESCO (1998), no artigo 11, alínea b, infere:

A qualidade requer também que o ensino superior esteja caracterizado por sua dimensão internacional: o intercâmbio de conhecimentos, a criação de sistemas interativos, a mobilidade de professores e estudantes e os projetos de investigação internacionais, ainda quando se tenha devidamente em conta os valores culturais e as situações nacionais. (UNESCO, 1998).

A mobilidade, como fenômeno, engloba hoje vários fatores e processos que, segundo Castro e Neto (2012), estão na base do sistema produtivo e no cotidiano das pessoas, envolvendo todo o sistema de transporte, a gestão desses espaços, as interações espaciais até as dinâmicas geográficas específicas. A mobilidade não envolve apenas o movimento de deslocamento; ela é muito mais ampla, pois é social e envolve estruturas, meios, culturas e significados. 
Portanto não se trata apenas da realização de estudos em outro país, mas compreende a relação internacional em outros aspectos interligados, como o social e o cultural, uma vez que, no caso das universidades, o movimento de mobilidade estudantil surge com o intuito de "[...] estabelecer uma amplitude nas dimensões intelectual, cultural, social, científica e tecnológica para a formação de cidadãos preparados para enfrentar os desafios do novo milênio" (STALLIVIERI, 2004, p. 38), além de ampliar acordos interinstitucionais.

Segundo Knight (2007), frequentemente, o termo mobilidade acadêmica é confundido com internacionalização, entretanto a mobilidade é apenas uma parte do processo de internacionalização que se refere ao movimento de pessoas, conhecimentos, programas, fornecedores, políticas, ideias, programas, projetos, pesquisas e serviços através das fronteiras jurisdicionais nacionais ou regionais. De acordo com Nascimento (2017), a maneira como a mobilidade ocorre nas Instituições de Ensino Superior (IESs) é reflexo das políticas adotadas pelos países enquanto estratégia para o seu desenvolvimento, considerando as ações desenvolvidas pelos países que são tidos como receptores e emissores de estudantes.

Esse olhar nos permite pensar que os países periféricos fornecem "cérebros" e recursos financeiros para países centrais e consomem os "produtos educacionais" dos países considerados ativos no comando da internacionalização. Como ressaltam Lima e Contel (2011, p. 31), "É possível dizer que nos países periféricos as dificuldades para internalizar o processo de desenvolvimento, ou de acumulação de capital, são bem maiores, pois a maior parte da infraestrutura desses territórios é extravertida". Algumas dificuldades que caracterizam essa "extraversão" consistem na infraestrutura muito mais voltada para a exportação do que para as necessidades internas, visto que formam circuitos de exportação e dificultam a consolidação de seus respectivos mercados internos; dificuldade nos processos econômicos e políticos, dados o contexto de decisão e a acumulação no exterior, entre outras.

Para Castro e Neto (2012), a maneira como as regiões e os países se inserem no cenário mundial, considerando a sua importância política, desenvolvimento econômico, científico e tecnológico, influencia o processo de receptividade dos alunos no que se refere à mobilidade acadêmica. A valorização do conhecimento na sociedade atual fomenta a pesquisa e a formação de profissionais, considerados grandes potenciais aos países, que passam a priorizar o campo tecnológico, 
aumentando as disparidades entre os países centrais e periféricos. Portanto faz-se necessária uma análise mais aprofundada de como alcançar um equilíbrio mais adequado de interesses e necessidades entre o local, o regional, o nacional, o internacional e o global.

O entendimento de que a internacionalização ativa é, principalmente, desenvolvida pelos países centrais, conforme advogam Lima e Maranhão (2009), justifica-se pela mobilidade internacional de estudantes, preferencialmente para os países desenvolvidos, entre os quais se destacam: Estados Unidos da América, Reino Unido, Alemanha, França, Austrália, Canadá e Japão. Ainda, a mobilidade estudantil é acentuada nesses países em razão de haver um sistema de Ensino Superior consolidado e pelo seu poder econômico.

Os países reconhecidos pela capacidade de atração e acolhimento de acadêmicos além de capitalizar recursos financeiros diretos e indiretos (sem penalizar os estudantes nacionais e o orçamento do Estado), contribui para: ampliar a rede mundial de influência cultural e política (a); selecionar os melhores cérebros (b); beneficiar-se de mão de obra qualificada (mesmo que por tempo determinado) (c); promover transferência de tecnologia (d); criar ambiente de aprendizagem de caráter multicultural (e); renovar a pesquisa e resistir à fuga de cérebros (f); além de enfrentar a imigração não-controlada. (LIMA; MARANHÃO, 2009, p. 588).

Sob esses entendimentos, Knight (2014) alerta sobre os principais problemas e desafios relacionados principalmente com os programas de mobilidade, enfatizando que, embora existam novos projetos que visem a ampliar o acesso ao Ensino Superior e atender ao interesse por credenciais estrangeiras e empregabilidade, há problemas sérios relacionados com a qualidade da oferta acadêmica, a integridade dos novos "prestadores de serviço" e o reconhecimento dessas credenciais. Segundo ela, o aumento do número de "fábricas de diplomas estrangeiros" e Accreditation Mill (certificados de programas e instituições não reconhecidas pelo governo) e instituições com fins lucrativos (não reconhecidas pelas autoridades nacionais) são realidades enfrentadas por alunos, pais, empregadores e docentes. E questiona:

Quem há duas décadas imaginaria que a educação internacional estaria lutando para lidar com diplomas falsos e certificados não reconhecidos? Claro, é igualmente importante reconhecer o desenvolvimento de inovações por novas instituições e universidades de valor inquestionável, que estão 
oferecendo programas de alta qualidade e legítimos através de novos tipos de acordos e parcerias. A eterna questão de equilibrar custos, qualidade e acesso desafia de forma significativa os riscos e benefícios da educação entre fronteiras. (KNIGHT, 2014, p. 2).

Pela razão exposta e, a partir do surgimento do discurso ideológico, baseado na defesa da sociedade do conhecimento, a relação ativa e passiva entre países torna-se bastante intensa no campo educacional. Nesse contexto, a UNESCO (2008, p. 7) diz que "estamos assistindo à emergência de um novo paradigma econômico e produtivo no qual o fator mais importante deixa de ser a disponibilidade de capital, trabalho, matérias-primas ou energia, passando a ser o uso intensivo de conhecimento e informação". Também deixa claro que o conhecimento passou a ser considerado força produtiva, levando, na sociedade capitalista, à disputa por sua posse.

Nessa perspectiva, Maués e Bastos (2016) entendem que a internacionalização ganha fórum privilegiado ao estar relacionada a um contexto da globalização e da mundialização da economia, em virtude do entendimento que passa a ser dado a esse processo. No contexto global, chama a atenção o exemplo da União Europeia, olhada no contexto do Processo de Bolonha, que inspira alguns a ver na educação uma forma de criação do conhecimento para utilizá-la no fortalecimento dos países-membros dessa comunidade, sendo vista, por uma parcela, como um grande retrocesso e retirada da autonomia da universidade, e por outra, como uma possibilidade de integração entre povos e países.

A UNESCO, no preâmbulo da Declaração Mundial sobre Educação Superior no Século XXI: visão e ação - 1998, corrobora que:

A qualidade requer também que a educação superior seja caracterizada por sua dimensão internacional: intercâmbio de conhecimento, criação de redes interativas, mobilidade de professores e estudantes e projetos de pesquisa internacionais, levando sempre em conta os valores culturais e as situações nacionais. (UNESCO, 1998)

A Educação Superior no século XXI foi o foco das conferências internacionais que, com esse processo de construção histórica, culminou na determinação de políticas que valorizaram o fenômeno da internacionalização como um ponto que auxilia no desenvolvimento das instituições e dos que dela participam.

Um ano depois da Declaração da Unesco, ministros da educação de países europeus reuniram-se, em 19 de junho de 1999, na cidade de Bolonha, para 
assinar a Declaração de Bolonha, um marco histórico perante o novo modelo de Educação Superior. Morgado (2009) explica o que de fato a declaração - que se torna, na prática, um processo de mudança para as instituições - tem como objetivo, afirmando que:

[...] Constituindo um marco preponderante na reforma das instituições de ensino da Europa, o Processo de Bolonha traça como objetivos principais a edificação de um espaço europeu de ensino superior - que viabilize a internacionalização das universidades, facilite a mobilidade de alunos e docentes, promova a empregabilidade dos cidadãos europeus e concorra para o desenvolvimento económico, social e humano da Europa -, a consolidação e enriquecimento da cidadania europeia e o aumento da competitividade com os outros sistemas de ensino do mundo (em particular os dos Estados Unidos e do Japão). (MORGADO, 2009, p. 50)

Neste modelo de Educação Superior, a internacionalização, especificamente o intercâmbio, tornou-se estratégia, como afirma Spears (2014, p. 152 apud CUNHA, 2016, p. 37):

O intercâmbio cultural ganhou um tom diferente daquele denominado pelo desenvolvimento da língua estrangeira e de enriquecimento cultural e passou a objetivar a preparação de jovens para uma economia globalmente competitiva, orientada pelas áreas estratégicas da ciência, tecnologia, engenharia e matemática.

De acordo com a Organização para a Cooperação e Desenvolvimento Econômico (OCDE, 2012), a estimativa de aumento da mobilidade acadêmica para o ano de 2025 é de 7,2 milhões de casos, sendo que, em 2010, havia 4,1 milhões de casos. Esse processo de internacionalização traz grandes benefícios para o melhoramento de um perfil profissional de competência, conforme enfatiza a CAPES (BRASIL, 2017, p. 31):

A mobilidade é de extrema importância na Educação Superior, pois permite a preparação de estudantes que se tornarão profissionais com visões globalizadas; igualmente é importante pelos conhecimentos que o estudante, professor ou pesquisador aporta mediante seu retorno à Instituição, ao seu grupo de pesquisa e laboratório, capaz de impactar muitos outros que não tiveram a oportunidade de sair do país.

Sob esse entendimento, de que a internacionalização pode impactar na vida dos estudantes, fizemos um estudo na URI - uma Instituição Comunitária, 
situada no interior do Estado do Rio Grande do Sul, no Brasil, e buscamos compreender a mobilidade como um de seus pilares para fortalecimento da qualidade de educação.

\section{A MOBILIDADE ACADÊMICA NA URI: OPORTUNIDADES?}

A URI é uma Universidade Regional, Integrada, Comunitária e multicampi, criada em 1992, a partir da fusão de IESs isoladas, organizadas pela comunidade regional; tem sua raiz comunitária e regional, por isso, está sempre comprometida com o desenvolvimento das localidades onde atua, reconhecendo que precisa preparar os indivíduos para os desafios encontrados em nível local, regional, estadual, nacional e internacional.

Sua principal missão é "Formar pessoal ético e competente, inserido na comunidade regional, capaz de construir conhecimento, promover a cultura, o intercâmbio, a fim de desenvolver a consciência coletiva na busca contínua da valorização e solidariedade humanas", que está ancorada nos princípios de ética, corresponsabilidade, qualificação institucional, inovação, desenvolvimento regional e da vida, gestão democrática, sustentabilidade e internacionalização, o que demonstra que a internacionalização é parte instituinte da URI (PDI, 2016-2020), corroborando com o que afirma Stallivieri (2009, p. 20) acerca do tema:

[...] desenvolvimento de profissionais que possam exercer suas atividades em qualquer parte do mundo; que possam se comunicar com estrangeiros de qualquer nacionalidade, utilizando pelo menos uma língua de comunicação internacional; que tenham o entendimento de que não existe uma cultura melhor do que a outra, mas que elas são apenas diferentes; que atuem com tolerância e flexibilidade diante do que lhes é desconhecido; que saibam reagir positivamente diante de obstáculos e dificuldades; e que sejam protagonistas de um momento fundamental para os rumos da humanidade, que vê na educação intercultural uma forma mais rápida e eficaz de buscar a paz entre as nações.

Assim, a URI, em seus processos de internacionalização, mostra-nos a mobilidade como um fator importante para a instituição. De acordo com o Plano de Desenvolvimento Institucional (PDI, Resolução n. 2107/CUN/2015), observamos que nos objetivos e nas metas se destaca a questão de "Implementar e gerar parcerias, estimular o intercâmbio com instituições que apresentam os seguimentos 
sociais, enfatizando a mobilidade acadêmica e a cooperação institucional" (URI, 2015b, p. 8).

Documentos da universidade dão ciência quanto às modalidades de intercâmbio na URI, apresentando cinco modalidades: "I. Intercâmbio de estudos; II. Intercâmbio científico ou de pesquisa; III. Intercâmbio cultural ou linguístico; IV. Intercâmbio de dupla diplomação; V. Intercâmbio para estágios de Graduação, Pós-Graduação e de Pós-Doutorado". (URI, 2015a). Essas são possibilidades concretas para docentes e discentes agregarem, entre as diversas experiências que vivem na Universidade, uma visão mais ampliada do mundo.

Sob essas perspectivas, é possível assegurarmos que a URI, em sua trajetória histórica, incentiva e aproxima, através de experiências e diálogo, o intercâmbio, principalmente no espaço ibero-americano, em que a integração ocorre pela aproximação e pelas convergências entre culturas e trajetórias, buscando a cooperação internacional.

A perspectiva do intercâmbio discente e docente, assim como a possibilidade de participação em grupos de pesquisa nacionais e internacionais, passando por ações de extensão e ensino, nasce pela missão da instituição e tem desafiado a URI a construir possibilidades de internacionalização, as quais, embora incipientes, vêm nascendo a partir dos convívios e contatos docentes com seus pares, dando vida a convênios com inúmeras instituições de diversos países que, por muito tempo, tiveram uma função muito mais protocolar do que de possibilitar trocas entre instituições, países, professores e acadêmicos.

Assim, a internacionalização e a mobilidade acadêmica fazem parte da história de existência da URI, representando, sim, oportunidades que ampliam o olhar da Universidade sobre o mundo, muito embora não tenha, em tempos passados, recebido o destaque que vem recebendo nesse momento da história, fruto de diversos fatores, entre eles, o próprio olhar das políticas públicas para essa temática, que é tão relevante, como foi o caso da criação e implementação do Programa Ciência sem Fronteiras, do Convênio Santander Universidade e de convênios com universidades da Itália, conforme demonstram os gráficos abaixo: 
Gráfico 2- Alunos por curso e por país que fizeram mobilidade entre 2013-2019

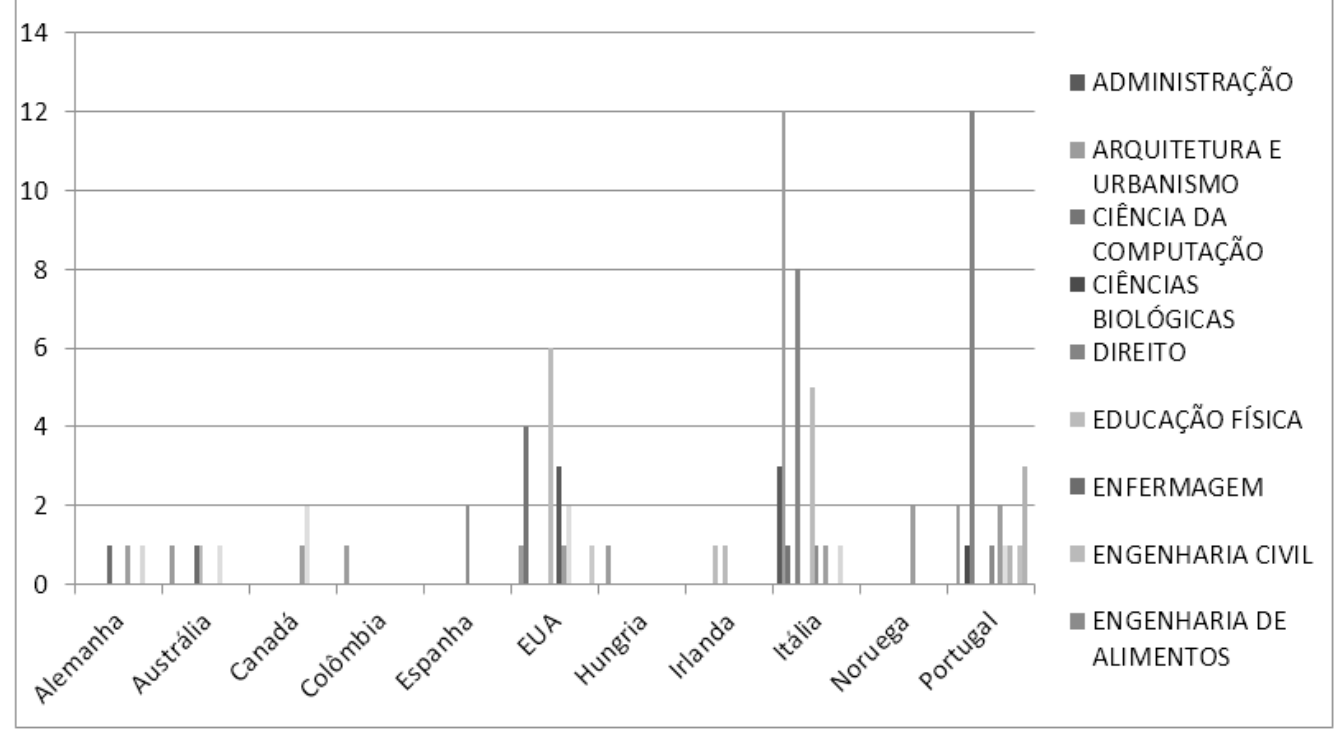

Fonte: Dados da Reitoria da URI (2019). 
Tabela 1 - Tabela geral

\begin{tabular}{|c|c|c|c|c|c|c|c|c|c|c|c|c|c|c|c|c|c|c|}
\hline Cursos & 充 & 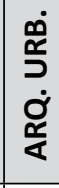 & $\mid \begin{array}{c}\dot{\sum} \\
\text { ப் } \\
\text { ய் }\end{array}$ & $\begin{array}{l}\dot{0} \\
\frac{0}{0} \\
\dot{U} \\
\dot{u}\end{array}$ & $\stackrel{\dot{a}}{\overline{0}}$ & $\begin{array}{l}u \dot{0} \\
\dot{\varphi}\end{array}$ & 这 & $\mid \begin{array}{l}\grave{i} \\
\dot{\bigcup} \\
\grave{u}\end{array}$ & 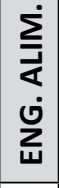 & نُ & 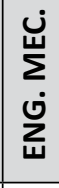 & 这 & $\dot{\Sigma}$ & ò & 迥 & ธ் & $\begin{array}{l}\dot{0} \\
\underline{z} \\
\dot{\bar{\sigma}}\end{array}$ & $\begin{array}{l}\overline{\widetilde{J}} \\
\stackrel{0}{\circ}\end{array}$ \\
\hline Alemanha & & & & & & & 1 & & & & 1 & & & 1 & & & & 3 \\
\hline Austrália & & 1 & & & & & 1 & 1 & & & & 1 & & & & & & 4 \\
\hline Canadá & & & & & & & & & & & 1 & 2 & & & & & & 3 \\
\hline Colômbia & & 1 & & & & & & & & & & & & & & & & 1 \\
\hline Espanha & & & & & & & & & 2 & & & & & & & & & 2 \\
\hline EUA & & 1 & 4 & & & & & 6 & & 3 & 1 & 2 & & & & & 1 & 18 \\
\hline Hungria & & 1 & & & & & & & & & & & & & & & & 1 \\
\hline Irlanda & & & & & & 1 & & 1 & & & & & & & & & & 2 \\
\hline Itália & 3 & 12 & 1 & & 8 & & & 5 & 1 & & 1 & & & 1 & & & & 32 \\
\hline Noruega & & & & & & & & & & & 2 & & & & & & & 2 \\
\hline Portugal & & 2 & & 1 & 12 & & & & 1 & & 2 & 1 & 1 & & 1 & 3 & & 24 \\
\hline Gráfico 2 & 3 & 18 & 5 & 1 & 20 & 1 & 2 & 13 & 4 & 3 & 8 & 6 & 1 & 2 & 1 & 3 & 1 & 91 \\
\hline $\begin{array}{l}\text { Total de } \\
\text { inscritos }\end{array}$ & 3 & 23 & 8 & 1 & 20 & 1 & 3 & 24 & 6 & 5 & 22 & 10 & 3 & 3 & 1 & 4 & 6 & 143 \\
\hline
\end{tabular}

Legenda: ADM.: Administração; ARQ. URB.: Arquitetura e Urbanismo; CIE. COM.: Ciência da Computação; CIE. BIO.: Ciências Biológicas; DIR.: Direito; ED. F.: Educação Física; ENF.: Enfermagem; EGN. CIV.: Engenharia Civil; ENG. ALIM.: Engenharia de Alimentos; ENG. ELE.: Engenharia Elétrica; ENG. MEC.: Engenharia Mecânica; FAR.: Farmácia; MAT.: Matemática; ODON.: Odontologia; PED.: Pedagogia; PSI.: Psicologia; QUI. IND.: Química Industrial.

Fonte: Elaborado pelas autoras.

Os dados dão conta de que, entre os anos de 2013 e 2019, noventa e um (91) alunos foram selecionados na URI para fazer intercâmbio em onze (11) países de várias partes do mundo, de um total de cento e quarenta e três (143) inscritos, o que dá uma média de 13 acadêmicos, por ano, buscando sua qualificação fora do país.

A pesquisa foi submetida, por meio de questionário inserido no Google Forms, a professores e alunos e os dados obtidos merecem atenção, pois são reveladores de aspectos importantes do processo de internacionalização na URI. 
Primeiramente, trazemos alguns dos dados referentes às questões encaminhadas aos professores. Ao serem questionados (questão 3) sobre sua participação em eventos fora do país, 94,4\% afirmam já ter participado e 5,6\%, não. Se tomarmos em conta a região em que estamos inseridos, distante dos grandes centros, sem infraestrutura de aeroporto, com as dificuldades que são enfrentadas no cotidiano, entre elas as econômicas, deslocar-se ao exterior demanda motivação do docente pesquisador, grande comprometimento com a pesquisa e incentivo da universidade. Ainda assim, uma porcentagem significativa de docentes já participou de eventos fora do país, o que os insere em ações de internacionalização, compreendendo e fazendo o processo acontecer.

Entre os docentes que participaram de eventos fora do país, quando questionados sobre o país onde se situava o evento, foram citados, em ordem crescente de participação: Portugal, Espanha e Argentina, o que dialoga com a valorização de parcerias com o panorama ibero-americano.

Esse dado corrobora que pode haver uma relação entre a participação docente em eventos e cooperação acadêmica internacional no âmbito da pesquisa, sendo que $77,8 \%$ dos respondentes afirmam já ter participado de projetos de pesquisa conjuntos com universidades de outros países, enquanto $22,2 \%$ responderam que não haviam participado ainda.

A pesquisa é um fator que nos traz uma perspectiva de aprendizagem, solidariedade, de olhares diferentes sobre um tema comum, o que possibilita ampliar horizontes sobre ideias, metas e, também, avanços para novas concepções e conceitos. Nesse particular, há espaço para crescer, ainda mais, a partir das pesquisas em conjunto com professores de universidades de outros países.

A questão sobre a participação docente em projetos de pesquisa complementa-se com essa (questão seis), que dá conta de buscar conhecer a quantidade de projetos de pesquisa com cooperação internacional que os professores já teriam participado. Os dados mostram-nos que 38,9\% já participaram de um projeto de pesquisa; 33,3\% tiveram participação em dois projetos de pesquisa; 16,7\% não tiveram participação; 5,6\% participaram em quatro; e 5,6\%, em mais de cinco. Quando analisamos os números da participação, percebemos que a inserção em projetos com cooperação internacional em número de projetos denota que a vivência do professor não acompanha a intensidade de suas relações com eventos e com parceiros de outras instituições. 
Nessa perspectiva, vários fatores poderiam ser apontados, mas a questão econômica, predominantemente, é a que mais impacta nesse momento da história. Pesquisas conjuntas, viagens internacionais, entre outros modos de convivência internacional, têm um custo elevado, que nem sempre corresponde à capacidade institucional e pessoal.

Um dado importante aponta que a área com maior número de projetos de pesquisa em cooperação internacional na URI é a de Ciências Humanas. Esse fato pode estar relacionado à história da universidade, que é marcada, desde seu início, pelos Cursos de Licenciatura (Letras, Pedagogia e História), a partir dos quais vieram as primeiras pós-graduações lato sensu e, por fim, o stricto sensu, por meio do Programa de Pós-Graduação em Educação, com Mestrado e Doutorado. Assim, a participação em projetos de pesquisa com cooperação internacional, nesta área, chega a um percentual de $88,9 \%$ dos projetos. Nas demais áreas, 5,6\% são de Ciências Biológicas e 5,6\%, da área de Ciências Exatas e da Terra. Os dados revelam um grande avanço na área de Ciências Humanas na URI; no entanto esta área não é definida como área prioritária para internacionalização na Instituição e nem nos editais de projetos advindos de órgãos de fomento externos.

De acordo com a Capes (BRASIL, 2017), as instituições com grande número de pós-graduação, as quais têm um grande aproveitamento de cotas de Programa de Doutorado Sandwich, indicam as áreas de Ciências da Saúde e Engenharia e Tecnologias como áreas prioritárias para a internacionalização, já as instituições com menor número de pós-graduação indicam a área de Ciências da Saúde como área prioritária e, logo após, a área de Ciências Humanas como segunda grande área prioritária.

Corroborando essas questões, ao serem questionados sobre a importância da participação de um docente/pesquisador em ações de internacionalização, a maioria respondeu que participar de tais ações permite que a experiência profissional e pessoal seja mais vasta, enriquecendo a formação do sujeito, a pesquisa e a cultura, permitindo novas formações de redes de pesquisa, contribuindo para o avanço da ciência.

Os dados apontam na direção do que acenava Moreira (2012), sobre a lentidão e a falta de estratégias da reação das estruturas políticas sobre as crises vividas tanto por sociedades ocidentais que perderam impérios como as socieda- 
des já libertadas, mas que buscaram e buscam, inquietamente, por orientação. Nesse particular, pronuncia-se sobre a internacionalização como a quarta missão da Universidade, afirmando:

A quarta dimensão da Universidade - depois de investigar, ensinar e gerir o saber e o saber fazer, é reconstruir o mundo novo, porque o Cisne Negro da viragem do milénio anarquizou o velho e exige a identificação, salvaguarda, fortalecimento e estratégia inovadora das instituições que guardam o poder do verbo, que faremos para sobreviver para organizar o caos. São essas instituições, em primeiro lugar de ideias de obra ou de empresa que ligam as gerações pela tradição e cimentam o futuro pela investigação, pelo saber, pelo saber fazer, e pela sabedoria, isto é, a restruturação de uma escala de valores que assumem a quarta dimensão. (MOREIRA, 2012, p. 13).

As perspectivas de Santos e Almeida Filho (2012) vão na direção da internacionalização como a quarta missão da Universidade, quando essa, ao repousar em bases materiais e institucionais sólidas, terá possibilidades de responder aos desafios do nosso tempo, tendo a capacidade de mobilizar a busca pelos objetivos: "reforçar projetos conjuntos e integradores; dar maior dimensão às suas atividades de formação, de pesquisa e de inovação; conduzir uma agenda própria de diplomacia cultural universitária; contribuir para a consolidação de Espaços Integrados do Conhecimento" (SANTOS; ALMEIDA FILHO, 2012, p. 145). Esses objetivos deverão estar fortemente alicerçados no interior das universidades para que a internacionalização faça avançar o conhecimento. Sob essa ótica, vemos que os alunos entendem esse processo como possibilidade de aprendizagens e trocas.

Nesse segundo momento, trazemos algumas das questões respondidas através de questionário enviado aos discentes da graduação da URI, do campus de Frederico Westphalen, e aos acadêmicos da URI de todos os campi que realizaram intercâmbio.

Entre os questionamentos, está a questão: o que os discentes entendem por internacionalização? Ao responderem, restou claro que a maioria dos alunos compreende a internacionalização como trocas em todos os sentidos, como compartilhamento e relações, sendo culturais, políticas, econômicas ou sociais. Muitos, ainda, citam o intercâmbio e desenvolvimento pessoal.

Perguntados sobre as ações de internacionalização que a Universidade desenvolve, 29,3\% dos alunos desconhecem tais ações, 23,9\% ficam sabendo das 
ações por professores/coordenadores dos cursos de Graduação, outros 23,9\% ficam sabendo pelo site da universidade, $13 \%$ por meio das redes sociais, 2,2\% por e-mail e 1,1\% conhecem por intermédio de colegas que já participaram de programas de mobilidade. Pode-se observar que a disseminação das informações precisa ser melhorada, pois ainda se apresenta insuficiente, de modo a atingir todos os acadêmicos para que se apropriem do que a instituição desenvolve. Isso se caracteriza como um desafio para a instituição que precisa inovar na forma de comunicar as possibilidades concretas de internacionalização, de modo que essa se consolide na universidade.

Ao serem perguntados sobre o interesse de realizar intercâmbio, 94,6\% afirmam que gostariam de realizar intercâmbio, 5,4\% afirmam não ter interesse, sendo a principal finalidade para realizar o intercâmbio o aprofundamento de estudos, apontado por $67,8 \%$ dos participantes, seguidos de $11,1 \%$ que desejam conhecer novas culturas, 7,8\% em busca de aprimorar a língua e 5,6\% para turismo.

Entre os alunos respondentes, 88\% afirmam não ter realizado intercâmbio, apenas $12 \%$ já realizaram ou estão realizando. Isso demonstra, de acordo com as respostas anteriores, que entre o sonho e a realidade há uma distância, mostrando também que reflete no perfil de aluno que a instituição possui. No caso da URI, estamos falando de uma maioria absoluta de alunos trabalhadores, que trabalha durante o dia e estuda à noite, o que dificulta sair do ambiente de trabalho para realizar uma viagem de estudos de longo, médio ou, até, de curto prazo.

Esses indicadores têm relação com as dificuldades apontadas pelos alunos em relação a poder participarem de ações de internacionalização na Universidade; $58,7 \%$ responderam que a principal dificuldade é a falta de recursos; $9,8 \%$ responderam que é a burocracia, 8,7\%, em decorrência da falta de tempo; e 4,3\% não querem atrasar os estudos. O restante que optou por dissertar sua resposta enquadra-se nas dificuldades referentes à falta de recursos, não querer atrasar os estudos e impossibilidade de sair do emprego por um período.

Quando o questionamento foi a língua, a fluência em outro idioma, a maioria não tem fluência em língua estrangeira, alguns são fluentes, outros têm nível intermediário, leem, compreendem e falam a língua espanhola, seguido então do segundo idioma mais citado, o inglês, e também o italiano. 
Quando perguntados sobre a importância da internacionalização para a formação do sujeito na atuação profissional, perante as respostas, todas subjetivas, pudemos perceber que a maioria afirma que a internacionalização amplia visões de mundo, permite criar maior facilidade na resolução de problemas, melhora o currículo profissional, possibilita adquirir conhecimento diferenciado, proporcionando solidez na autonomia, construção da formação crítica, e cria responsabilidades, mas alguns afirmam que, dependendo da área de formação, a internacionalização fica como mais uma experiência de vida, sendo a internacionalização irrelevante para alguns setores de áreas de formação.

Com os dados que conseguimos coletar de alunos e professores, conseguimos construir um panorama sobre o processo de internacionalização na instituição estudada, ainda que esse estudo precise ser aprofundado porque não tem a pretensão de ser definitivo.

\section{FINALIZANDO...}

De acordo com as produções teóricas analisadas até o momento, os dados empíricos obtidos e as análises feitas nos documentos legais da universidade, concluímos que a internacionalização é um fenômeno que possui seu conceito em permanente evolução, sob diferentes perspectivas; tal fenômeno, com diferentes faces, precisa ser compreendido e incorporado como princípio institucional, ação presente na URI. Por mais que os processos de internacionalização ainda sejam incipientes, esta pesquisa nos fez identificar desafios e conquistas da URI.

Estudos de documentos da IES demonstram os avanços que as ações pensadas nessa área vêm sofrendo, passando por mudanças que têm um significado importante para a consolidação da internacionalização, fato que denota a importância também do avanço conceitual.

Vale destacar que os intensos debates sobre a temática têm provocado um amadurecimento do processo, permitindo que o entendimento sobre o que seja internacionalização passe de uma visão, inicialmente, mais restrita à ideia de intercâmbio de acadêmicos e professores, para acrescentar a ela a construção de convênios, eventos, acordos e termos que tenham seus nascedouros a partir dos desejos e das necessidades de professores ou acadêmicos, referendados 
pelos Reitores, para se tornarem ações efetivas que nascem no bojo dos grupos de pesquisa, das relações profissionais e pessoais entre colegas que comungam de temáticas de pesquisa e interesses de estudos comuns.

Sob essa perspectiva, podemos afirmar que novos cenários na internacionalização estão sendo construídos, dentro das características próprias de uma universidade comunitária, como a em que desenvolvemos nossos estudos.

\section{REFERÊNCIAS}

AZEVEDO, M. L. N. Internacionalização ou transnacionalização da educação superior: entre a formação de um campo social global e um mercado de ensino mundializado. Crítica Educativa, Sorocaba, v. 1, n. 1, p. 56-75, jan./jun. 2015.

BRASIL. Ministério da Educação. Coordenação de Aperfeiçoamento de pessoal de Nível Superior. A internacionalização na Universidade Brasileira: resultados do questionário aplicado pela Capes. Brasília, 2017. Disponível em: https://www.capes.gov.br/images/ stories/download/diversos/A-internacionalizacao-nas-IES-brasileiras.pdf. Acesso em: 12 abr. 2018.

CASTRO, A. A.; NETO, A. C. O ensino superior: a mobilidade estudantil como estratégia de internacionalização na América Latina. Revista Lusófona de Educação, Portugal, v. 21, p. 69-96, 2012. Disponível em: revistas.ulusofona.pt/index.php/rleducacao/article/ view/3082. Acesso em: 26 maio 2018.

CHARLE, C.; VERGER, J. História das universidades. São Paulo: UNESP, 1996.

CUNHA, M. I. da. Internacionalização e democratização: uma tensão na qualidade da Educação Superior? São Leopoldo: Oikos, 2016.

KNIGHT, J. A Time of Turbulence and Transformation for Internacionalization. CBIE Research, n. 14, p. 1-17, 2007. Disponível em: https://eric.ed.gov/?id=ED549870. Acesso em: 5 ago. 2018.

KNIGHT, J. Internationalization: elements\&checkpoints. Ottawa: Canadian Bureau for International Education, 1994.

KNIGHT, J.; DE WIT, H. Internationalization remodeled: definition, approaches end rationales. Journal of Studies in Education, Washington, v. 8, n. 1, p. 5-31, jan./mar. 2004.

KNIGHT, J. Entrevista com Jane Knight: Universidades apostam na internacionalização. Jornal Extra Classe, edições impressas, jul. 2014. Disponível em: https://www.extraclasse. 
org.br/edicoes/2014/07/Universidades-apostam-na-internacionalizacao/. Acesso em: 25 jul. 2018.

LIMA, M. C.; CONTEL, F. B. Internacionalização da educação superior, nações ativas, nações passivas e a geopolítica do conhecimento. São Paulo: Alameda, 2011.

LIMA, M. C.; MARANHÃO, C. M. S. A. O sistema de educação superior mundial: entre a internacionalização ativa e passiva. Revista da Avaliação da Educação Superior, Campinas, v. 14, n. 3, p. 583-610, nov. 2009. Disponível em: http://www.scielo.br/scielo. php?pid=S1414-40772009000300004\&script=sci_abstract\&tlng=pt. Acesso em: $26 \mathrm{abr}$. 2018.

MAUÉS, O. C. BASTOS, R. dos S. As políticas de educação superior na esteira dos organismos internacionais. Revista Brasileira de Política e Administração da Educação, v. 32, n. 3, p. 699-717, set./dez. 2016. Disponível em: http://seer.ufrgs.br/index.php/rbpae/article/ view/68570. Acesso em: 5 abr. 2018.

MORGADO, J. C. Processo de Bolonha e Ensino Superior num mundo globalizado. Educação e Sociedade, Campinas, v. 30, n. 106, p. 37-62, jan./abr. 2009.

MOREIRA, A. Prefácio. In.: SANTOS, F. S.; ALMEIDA FILHO, N. A quarta missão da Universidade: internacionalização universitária na sociedade do conhecimento. Brasília: Editora Universidade de Brasília; Coimbra: Imprensa da Universidade de Coimbra, 2012.

MOROSINI, M. C. Estado do conhecimento sobre internacionalização da educação superior: conceitos e práticas. Educar, Curitiba, n. 28, p. 107-24, 2006.

NASCIMENTO, M. E. M. A internacionalização do ensino superior e a formação inicial de professores: um estudo do Programa Licenciaturas Internacionais na UFRN (2010-2013). Natal, 2017. Disponível em: https://repositorio.ufrn.br/jspui/ bitstream/123456789/24569/1/MariaEmanueleMacedoDoNascimento_DISSERT.pdf. Acesso em: 3 maio 2018.

ORGANIZAÇÃO PARA A COOPERAÇÃO E DESENVOLVIMENTO ECONÔMICO. Education at a Glance. OCDE, 2012. Disponível em: Disponível em: http://ww.oecd.org/edu/highlights. pdf. Acesso em: 13 jun. 2018.

SANTOS, F. S.; ALMEIDA FILHO, N. A quarta missão da Universidade: internacionalização universitária na sociedade do conhecimento. Brasília: Editora Universidade de Brasília; Coimbra: Imprensa da Universidade de Coimbra, 2012. 
SANTOS FILHO, J. C. Internacionalización de la educación superior: redefiniciones, justificativas y estrategias. Espaço Pedagógico, Passo Fundo, v. 25, n. 1, p. 168-89, jan./ abr. 2018. Disponível em: www.upf.br/seer/index.php/rep. Acesso em: 15 jan. 2019.

SPEARS, E. O valor de um intercâmbio: mobilidade estudantil brasileira, bilateralismo \& internacionalização da educação. Revista Eletrônica de Educação, São Carlos, v. 8, n. 1, p. 151-63, 2014. Disponível em: http://www.reveduc.ufscar.br/index.php/reveduc/article/ view/1026. Acesso em: 3 ago. 2018.

STALLIVIERI, L. As Dinâmicas de uma nova linguagem intercultural na mobilidade acadêmica internacional. Argentina: Universidad Del Salvador; Caxias do Sul: Universidade de Caxias do Sul, 2009. Disponível em: https://racimo.usal.edu.ar/52/1/Stellivieri.pdf. Acesso em: 21 abr. 2019.

STALLIVIERI, L. O processo de internacionalização nas instituições de ensino superior. Caxias do Sul: Assessoria de Relações Interinstitucionais e Internacionais, 2003. Disponível em: https://www.ucs.br/site/midia/arquivos/processo_internacionalizacao.pdf. Acesso em: 16 nov. 2017.

STALLIVIERI, L. Estratégias de internacionalização das universidades brasileiras. Caxias do Sul: Educs, 2004.

TREVISOL, M. G.; FÁVERO, A. A. As diversas faces da internacionalização: análise comparativa entre duas instituições comunitárias do sul do Brasil. Rev. Inter. Educ. Sup., Campinas, v. 5, 1-22, 2019.

UNESCO. Declaração mundial sobre Educação Superior no século XXI: visão e ação- 1998. Paris, 9 out. 1998.

UNESCO. Desafios da Universidade na Sociedade do Conhecimento. Brasília: UNESCO, 2008. Disponível em: http://unesdoc.unesco.org/images/0013/001344/134422por.pdf. Acesso em: 25 jul. 2018.

UNIVERSIDADE REGIONAL INTEGRADA DO ALTO URUGUAI E DAS MISSÕES. Conselho Universitário. Resolução n. 2114/CUN/2015. Dispõe sobre Programa de Internacionalização da URI. Erechim: URI, 2 out. 2015a.

UNIVERSIDADE REGIONAL INTEGRADA DO ALTO URUGUAI E DAS MISSÕES. Resolução $n$. 2107/CUN/2015. Plano de Desenvolvimento Institucional - 2016-2020: URI. Documentos oficiais. Erechim: URI, 31 de julho de 2015b. Disponível em: http://www.reitoria.uri.br/. Acesso em: dez. 2018. 
UNIVERSIDADE REGIONAL INTEGRADA DO ALTO URUGUAI E DAS MISSÕES. Resoluçãon. 2107/CUN/2015. Plano de Desenvolvimento Institucional - 2016-2020: URI. Documentos oficiais. Erechim: URI, 31 de julho de 2015b. Disponível em: http://www.reitoria.uri.br/. Acesso em: dez. 2019.

\section{Sobre as autoras:}

Silvia Regina Canan: Doutorado em Educação pela Universidade do Vale do Rio dos Sinos (UNISINOS). Mestrado em Educação pela Universidade Federal do Rio Grande do Sul (UFRGS). Graduação em Pedagogia pela Universidade Federal de Santa Maria (UFSM). Professora da Universidade Regional Integrada do Alto Uruguai e das Missões (URI) - Campus de Frederico Westphalen. Docente da Pós-Graduação Stricto Sensu em Educação - Nível Mestrado e Doutorado. Participou de inúmeros eventos na área da Educação como ouvinte e também apresentando trabalhos, possui publicações em anais de eventos com textos completos e resumos, e livros editados pela Editora da URI, pela Editora CRV, pela Mercado de Letras e Pela Editora Livre da Clacso e alguns capítulos em outros livros. Atualmente, é Diretorageral da URI - Campus de Frederico Westphalen. E-mail: silvia@uri.edu.br, Orcid: http://orcid.org/0000-0003-4504-3680

Edite Maria Sudbrack: Doutorado e mestrado em Educação pela Universidade Federal do Rio Grande do Sul (UFRGS). Estágio pós-doutoral pela UFRGS, com o projeto: "Assistência financeira da União aos estados e municípios na educação básica: política e políticas". Em estágio pós-doutoral na Universidade de Aveiro, Portugal. Graduação em Pedagogia pela Universidade Federal de Santa Maria. Pró-reitora de Ensino da Universidade Regional Integrada do Alto Uruguai e das Missões (URI). Docente do PPGEDU e professora na URI. Atua como coordenadora local do DINTER-UNISINOS/URI. E-mail: sudbrack@uri.edu.br, Orcid: http://orcid.org/0000-0002-9591-8038

Thais Campos da Silva: Acadêmica do Curso de Pedagogia da Universidade Regional Integrada do Alto Uruguai e das Missões (URI), Campus de Frederico Westphalen, RS. Estagiária no Setor de Avaliação Externa dos Cursos de Graduação da URI, Campus de Frederico Westphalen. Bolsista PROBIC/CNPq, desenvolvendo pesquisa sobre o tema "Internacionalização em processo: um estudo a partir da perspectiva da extensão", no Núcleo de Estudos e Pesquisas em Processos 
de Educação Superior (NEPPES). E-mail: thaixcampos07@gmail.com, Orcid: http://orcid.org/0000-0001-5584-1120

Recebido em 15 de outubro de 2019.

Aprovado em 14 de fevereiro de 2020. 